\title{
Avaliação da colonização nasal por Staphylococcus spp. resistente à oxacilina em alunos de enfermagem
}

Primeira submissão em 19/12/08 Última submissão em 09/07/09 Aceito para publicação em 11/08/09 Publicado em 20/10/09

\section{Evaluation of nasal colonization for oxacillin resistant Staphylococcus spp. in nursing students}

Eliane Patricia Lino Pereira'; Maria de Lourdes Ribeiro de Souza da Cunha ${ }^{2}$

\begin{tabular}{|c|c|}
\hline unitermos & resumo \\
\hline $\begin{array}{l}\text { Staphylococcus } \\
\text { Portadores } \\
\text { Estudantes } \\
\text { Enfermagem }\end{array}$ & $\begin{array}{l}\text { Introdução: O gênero Staphylococcus é responsável por um grande número de infecções bacterianas } \\
\text { em humanos, principalmente no ambiente hospitalar. Objetivo: Diante dessas considerações, da } \\
\text { importância do cuidado de enfermagem e do controle de infecções hospitalares, este trabalho verificou } \\
\text { a taxa de portadores de S. aureus e estafilococos coagulase-negativa (ECN) resistentes a oxacilina } \\
\text { em alunos do curso de enfermagem durante a formação profissional. Materiais e métodos: Foram } \\
\text { coletadas amostras das fossas nasais de alunos do curso de enfermagem da Faculdade de Medicina } \\
\text { de Botucatu (FMB). Resultados: Das } 109 \text { amostras de Staphylococcus encontradas, } 30 \text { (27,5\%) foram } \\
\text { de Staphylococcus aureus e } 79 \text { ( } 72,5 \%) \text {, de ECN. Das } 79 \text { amostras de ECN submetidas às provas de } \\
\text { identificação, } 63 \text { ( } 79,7 \%) \text { foram da espécie S. epidermidis, nove }(11,4 \%) \text {, S. warneri, três (3,8\%), S. } \\
\text { haemolyticus, duas ( } 2,5 \%) \text {, S. capitis, uma ( } 1,3 \%) \text {, S. simulans e uma (1,3\%) S. lugdunensis. O teste de } \\
\text { suscetibilidade a antibióticos demonstrou } 100 \% \text { de sensibilidade às drogas nas amostras de S. aureus e, } \\
\text { entre as } 79 \text { amostras de ECN, } 10 \text { ( } 12,6 \%) \text { foram resistentes a oxacilina. A técnica de reação em cadeia } \\
\text { da polimerase (PCR) demonstrou resultado negativo para o gene mecA nas amostras de S. aureus e } 11 \\
\text { amostras positivas entre as espécies de ECN. Discussão: Não houve relação entre a taxa de portadores } \\
\text { de S. aureus e o envolvimento hospitalar durante a graduação, os resultados também demonstraram } \\
\text { maior incidência de resistência nas amostras de FCN semelhante anencontradona literatura científica }\end{array}$ \\
\hline
\end{tabular}

\section{abstract}

Introduction: The genus Staphylococcus is responsible for a great number of bacterial infections in human, mainly in hospital environment. Objectives: In view of these considerations and the importance of nursing care and nosocomial infection control, this study verified the rate of $\mathrm{S}$. aureus and coagulase-negative Staphylococci (CNS) carriers resistant to oxacillin in nursing students during their university course. Materials and methods: Nasal samples were collected from Nursing students at Botucatu School of Medicine - UNESP. Results: From 109 isolated samples of Staphylococcus, 30 samples (27.5\%) were Staphylococcus aureus and 79 samples (72.5\%) were CNS. From 79 identified CNS samples, 63 (79.7\%) were S. epidermidis, nine (11.4\%) S. warneri, three (3.8\%) S. haemolyticus, two (2.5\%) S. capitis, one (1.3\%) S. simulans and one (1.3\%) S. lugdunensis. The antibiotic susceptibility test showed $100 \%$ sensibility to the drugs in S. aureus samples and among 79 CNS samples, $10(12,6 \%)$ were resistant to oxacillin. The PCR technique demonstrated negative result for mecA gene in $\mathrm{S}$. aureus samples and 11 positive samples among CNS species. Discussion: There was no relation between the rate of $\mathrm{S}$. aureus carriers and nosocomial involvement during the course. The results also showed a higher incidence of resistance in CNS samples, which is seemingly reported in the scientific literature.

\section{key words}

Staphylococcus

Carriers state

Students

Nursing 


\section{Introdução}

O gênero Staphylococcus é responsável por um grande número de infecções bacterianas no homem, sendo dividido em dois grandes grupos com base na produção da enzima coagulase. O primeiro grupo, conhecido como Staphylococcus coagulase-positiva, é representado, principalmente, pelo Staphylococcus aureus. O segundo grupo, chamado estafilococos coagulase-negativa (ECN), é compreendido por várias espécies: $S$. epidermidis, S. haemolyticus, S. saprophyticus, S. lugdunensis, S. cohnii, S. schleiferi, S. simulans, S. hominis, S. warneri, S. capitis, S. caprae e S. xylosus(14).

O Staphylococcus é um dos membros patogênicos da microbiota normal do ser humano, em que existe como persistente ou transitório sem causar qualquer sintoma ${ }^{(15)}$. É encontrado em várias partes do corpo, tais como fossas nasais, mãos, garganta, intestinos, sendo as fossas nasais o principal reservatório da bactéria ${ }^{(21-22)}$.

As infecções estafilocócicas podem ser causadas por bactérias do próprio indivíduo (infecções endógenas) ou por amostras adquiridas de outros doentes ou portadores sadios (infecções exógenas)(15). A transmissão ocorre de pessoa para pessoa (infecção cruzada), por meio do contato indireto (via aérea) ou por contato direto, estando essa transferência na dependência da presença de uma fonte (doentes ou portadores)(4-18).

Os estafilococos também são conhecidos pela elevada capacidade de desenvolver resistência a vários antibióticos, principalmente dentro do ambiente hospitalar, onde esses medicamentos são amplamente utilizados. A principal droga de escolha para o tratamento é a oxacilina ou sua análoga, meticilina, pois possuem o mesmo mecanismo de ação( ${ }^{(6)}$.

O fato de os estafilococos, principalmente o S. aureus, serem capazes de causar infecções e estarem localizados no nariz de profissionais da saúde, com destaque para a equipe de enfermagem, prestadora de cuidados e com contato mais próximo dos pacientes, tem causado grande preocupação(21).

Diante dessas considerações, da importância do cuidado de enfermagem e do controle de infecções dentro do ambiente hospitalar, o objetivo deste estudo foi verificar a taxa de portadores de S. aureus e ECN resistentes a oxacilina em alunos do curso de enfermagem durante a formação profissional, quando são submetidos progressivamente às influências específicas do ambiente hospitalar, em decorrência das atividades programadas e desenvolvidas nas diferentes disciplinas da grade curricular do curso.

\section{Materiais e métodos}

\section{Amostragem}

O estudo foi realizado com alunos do curso de enfermagem da Faculdade de Medicina de Botucatu (FMB), Universidade Estadual Paulista (UNESP). Foram incluídos no estudo todos os alunos do curso de graduação em enfermagem, e excluídos aqueles que apresentaram qualquer sinal de infecção das vias aéreas superiores e que estavam usando antibióticos até um mês antes da data da coleta.

\section{Características dos alunos}

Foi preenchido um questionário para cada aluno estudado, contendo dados de identificação e envolvimento do aluno com instituições de saúde, antes e/ou durante a formação. Essa informação foi obtida tendo em vista a possível influência do contato prévio com o ambiente hospitalar na taxa de colonização dos alunos pelo $S$. aureus.

\section{Coleta e processamento do material clínico}

Foram coletadas amostras das fossas nasais dos alunos de enfermagem. Na coleta do material, foram utilizados swabs estéreis umedecidos com salina previamente esterilizada. Para a coleta, o swab foi introduzido na fossa nasal anterior, fazendo movimentos circulares delicados por três vezes.

Após a coleta, os materiais foram colocados no interior de tubos secos estéreis e imediatamente encaminhados ao Laboratório de Bacteriologia do Departamento de Microbiologia e Imunologia do Instituto de Biociências da UNESP, para realização de semeadura em placas contendo ágar Baird-Parker, meio seletivo para Staphylococcus. Após incubação a $37^{\circ} \mathrm{C}$ por 24 horas, as amostras foram submetidas ao procedimento de identificação dos microrganismos isolados.

\section{Identificação de Staphylococcus aureus}

Obedecendo às etapas de identificação microbiológica, as colônias foram submetidas à coloração de Gram, objetivando sua pureza e a observação de suas 
morfologia e coloração específicas. Após a confirmação das características das colônias, as linhagens foram submetidas às provas de catalase e coagulase ${ }^{(12)}$.

\section{Identificação de estafilococos coagulase- negativa}

Os isolados negativos para o teste da coagulase, ou seja, coagulase-negativas foram semeados em ágarsangue e corados pelo método de Gram, objetivando-se sua pureza e a observação de sua morfologia e coloração específica. Após a confirmação dessas características, as linhagens foram, novamente, submetidas às provas de catalase e coagulase. O gênero Staphylococcus foi diferenciado de Micrococcus, com base na prova de oxidação e fermentação da glicose e pela resistência à bacitracina $(0,04 \mathrm{U})$ indicada pela ausência de halo de inibição ou formação de halo de até $9 \mathrm{~mm}$ e pela sensibilidade à furazolidona $(100 \mu \mathrm{g})$ caracterizada por halos de inibição de 15 a 35 mm de diâmetro(12).

A identificação das espécies dos ECN foi realizada utilizando o método simplificado proposto por Cunha et $a l .^{(3)}$, conforme esquema de provas bioquímicas, o qual estabelece a realização de testes de utilização de açúcares: xilose, sacarose, trealose, manitol, maltose, lactose, crescimento anaeróbico em meio tioglicolato, redução de nitrato, produção de hemolisinas, urease e ornitina descarboxilase.

Para controle dos resultados dos testes, foram utilizadas as seguintes linhagens de $\mathrm{ECN}$ de referência internacional: S. epidermidis (ATCC 12228), S. simulans (ATCC 27851), S. warneri (ATCC 10209) e S. xylosus (ATCC 29979).

\section{Avaliação da atividade de drogas antimicrobianas in vitro - Técnica da difusão da droga em ágar (método Kirby-Bauer)}

O teste de sensibilidade às drogas antimicrobianas foi realizado pela técnica de difusão da droga em ágar a partir de discos impregnados conforme critérios recomendados pelo Clinical and Laboratory Standards Institute $(\mathrm{CLSI})^{(1)}$. Para o preparo dos inóculos, foram utilizadas culturas em caldo infusão de cérebro e coração $(\mathrm{BHI})$, previamente incubados por 4 a 6 horas e ajustadas anteriormente com a turbidez da escala 0.5 de Mac Farland. Os discos utilizados foram de oxacilina $(1 \mu \mathrm{g})$ e cefoxitina $(30 \mu \mathrm{g})$.

A interpretação de resistência à oxacilina foi realizada obedecendo aos valores definidos de acordo com o CLSI(1), sendo S. aureus e S. lugdunensis resistentes quando apre- sentarem medida de halo menor ou igual a $10 \mathrm{~mm}$ para 0 disco de oxacilina e menor ou igual a 21 para o disco de cefoxitina, e o ECN, exceto S. lugdunensis, quando a medida de halo for menor ou igual a $17 \mathrm{~mm}$ para o disco de oxacilina e menor ou igual a 24 para o disco de cefoxitina.

\section{Deteç̧ão do gene mecA de resistência à oxacilina em amostras isoladas de Staphylococcus aureus e ECN}

Extração do ácido nucleico

A extração do ácido nucleico total foi realizada com as amostras de $S$. aureus e ECN cultivadas em ágar-sangue, inoculadas individualmente em caldo $\mathrm{BHI}$ e incubadas a $37^{\circ} \mathrm{C}$ por $24 \mathrm{~h}$.

A extração foi realizada com o Kit GFX (Amersham Pharmacia Biotech), que consiste na digestão inicial das células de estafilococos com lisozima $(10 \mathrm{mg} / \mathrm{ml})$ e proteinase $K(20 \mathrm{mg} / \mathrm{ml})$. A seguir, $500 \mu \mathrm{l}$ da solução de extração foram adicionados à mistura, que foi centrifugada a $5.000 \mathrm{~g}$ por um minuto. Em seguida, o sobrenadante foi transferido para a coluna GFX e centrifugado a $5.000 \mathrm{~g}$ por um minuto. O líquido coletado foi descartado e $500 \mu \mathrm{l}$ de solução de extração foram adicionados novamente à coluna. Após centrifugação e descarte do líquido coletado, $500 \mu \mathrm{l}$ da solução de lavagem foram adicionados à coluna, que foi submetida à centrifugação a $14.000 \mathrm{rpm}$ por três minutos. A seguir, a coluna foi transferida para um tubo de $1,5 \mathrm{ml}$, e $200 \mu \mathrm{l}$ de água Milli $\mathrm{Q}$ aquecida a $70^{\circ} \mathrm{C}$ foi utilizada para a eluição. As amostras foram centrifugadas a $5.000 \mathrm{~g}$ por um minuto e a coluna de GFX, desprezada. O DNA extraído foi mantido a $-20^{\circ} \mathrm{C}$ até seu uso.

\section{Amplificação do ácido nucleico}

As reações em cadeia da polimerase ( $P C R$ ) foram realizadas em tubos de microcentrífuga de $0,5 \mathrm{ml}$ em volumes totais de $25 \mu \mathrm{l}$ contendo $1 \mu \mathrm{M}$ de cada primer (Tabela 1), $2 \mathrm{U}$ de Taq polimerase, $100 \mu \mathrm{M}$ de desoxiribonucleotídeos trifosfatados, 0,75 mM de $\mathrm{MgCl}_{2}$ e $150 \mathrm{ng}$ de ácido nucleico. A incubação foi realizada em termociclador apropriado, empregando os parâmetros descritos por Murakami et al. (17) que consistem de 40 ciclos de desnaturação a $94^{\circ} \mathrm{C}$ por trinta segundos, anelamento dos primers a $55,5^{\circ} \mathrm{C}$ por trinta segundos e extensão a $72^{\circ} \mathrm{C}$ por um minuto. Após completar os 40 ciclos, os tubos foram incubados a $72^{\circ} \mathrm{C}$ por cinco minutos antes de resfriar a $4{ }^{\circ} \mathrm{C}$. Em todas as 


\section{Tabela 1 Oligonucleotídeos para detecção do gene mecA}

$\begin{array}{cccc}\text { Função } & \text { Nome } & \text { Sequência de nucleotídeos 5'a 3' } & \text { Produto amplificado } \\ \text { Primer } & \text { mecA1 } & \text { AAA ATC GAT GGT AAA GGT TGG } & 533 \text { bp } \\ \text { Primer } & \text { mecA2 } & \text { AGT TCT GCA GTA CCG GAT TTG } & 533 \text { bp }\end{array}$

Fonte: MURAKAMI et al. ${ }^{(17)}$.

reações realizadas, foram utilizadas linhagens de referência internacional com controles positivo (S. aureus ATCC 33591) e negativo (S. aureus ATCC 29213).

\section{Visualização dos produtos amplificados}

A eficiência das amplificações foi monitorada pela eletroforese da reação em gel de agarose $2 \%$ preparado em tampão 0,5 X TBE e corado com Syber Safe. O tamanho dos produtos amplificados foi comparado com o padrão de $100 \mathrm{bp}$ e, posteriormente, os produtos foram fotografados sob transluminação ultravioleta.

\section{Análise estatística}

Para comparação das proporções entre as amostras de $S$. aureus resistentes e sensíveis a oxacilina e o ano de graduação dos estudantes foi utilizado o teste de $\chi^{2}$. O nível de significância para todos os testes foi fixado em $p<0,05$.

\section{Resultados}

\section{Amostragem e características dos alunos}

Participaram do estudo 104 alunos do curso de enfermagem e foram excluídos 21 alunos que não se enquadraram nos critérios de inclusão ou não aceitaram participar do estudo.

O questionário aplicado demonstrou (Tabela 2) que $80(76,9 \%)$ alunos estudados manifestaram algum tipo de infecção bacteriana durante a vida, os tipos de infecção mais frequentes foram orofaringite e amigdalite, 17 (16,3\%) alunos relataram ter sofrido internação devido ao quadro de infecção e $14(13,5 \%)$ alunos tiveram envolvimento com instituições de saúde anteriormente à graduação (técnico e auxiliar de enfermagem, trabalho voluntário). Quanto ao envolvimento atual, com exceção do primeiro ano de graduação (27 alunos), todos tiveram contato com 0 ambiente hospitalar.
Tabela 2

Características

$\begin{array}{llllll}\text { Características } & 1^{\circ} \text { ano } & 2^{\circ} \text { ano } & 3^{\circ} \text { ano } & 4^{\circ} \text { ano } & \text { Total } \\ & n(\%) & n(\%) & n(\%) & n(\%) & n(\%)\end{array}$

Envolvimento

anterior à

310

$3 \quad 11,1$

$4 \quad 16,6$

4

17,3

$14 \quad 13,5$

graduação

Infecção

bacteriana

2996,6

15

55,5

$18 \quad 75$

18

78,2

$80 \quad 76,9$

Internação

associada à

infecção

Envolvimento

atual

Total
$4 \quad 14,8$

$27 \quad 100$

$27 \quad 100$
$6 \quad 25$

$24 \quad 100$

$24 \quad 100$
$4 \quad 17,3$

$17 \quad 16,3$

$30 \quad 100$

100

FMB: Faculdade de Medicina de Botucatu; N: número de alunos. 


\section{Coleta e processamento do material clínico}

Foram coletadas 104 amostras das fossas nasais dos alunos incluídos no estudo. Previamente à coleta, houve uma explicação sobre projeto, coleta, entrega do termo de consentimento e do questionário para os alunos que aceitaram participar do estudo.

A coleta foi realizada pelo próprio aluno para evitar constrangimento, mas sempre com acompanhamento durante o procedimento, e imediatamente após a coleta os materiais foram encaminhados dentro de tubos estéreis ao Laboratório da Bacteriologia do Departamento de Microbiologia e Imunologia do Instituto de Biociências de Botucatu/UNESP para identificação.

\section{Identificação de Staphylococcus aureus e estafilococos coagulase-negativa}

Participaram do estudo 104 alunos do curso de enfermagem, entre os quais foram obtidas 109 amostras de Staphylococcus, pois em algumas culturas cresceram duas cepas diferentes. Entre essas, $30(27,5 \%)$ amostras foram de Staphylococcus aureus e 79 (72,5\%) amostras foram de ECN, sendo que, das amostras de ECN, 63 (79,7\%) foram identificadas como sendo da espécie Staphylococcus epidermidis, nove $(10,1 \%)$, S. warneri, três $(3,8 \%)$, S. haemolyticus, duas $(2,5 \%)$, S. capitis, uma $(1,3 \%)$, S. simulans e uma $(1,3 \%)$, S. lugdunensis (Figura 1). As taxas de portadores de Staphylococcus aureus divididas segundo os anos foram: primeiro ano (13 alunos, 43,3\%); segundo ano (três alunos, $11,1 \%$ ); terceiro ano (oito alunos, $33,3 \%$ ) e quarto ano (seis alunos, 26\%).

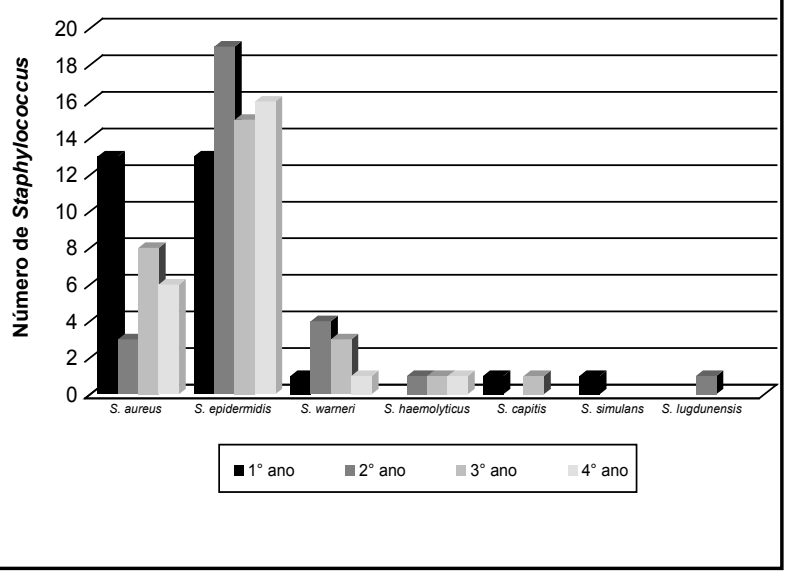

Figura 1 - Distribuição de S. aureus e espécies de ECN isoladas das fossas nasais de alunos do primeiro ao quarto ano do curso de enfermagem da FMB ECN: estafilococos coagulase-negativos; FMB: Faculdade de Medicina de Botucatu.

\section{Avaliação da atividade de drogas antimicrobianas in vitro - Técnica da difusão da droga em ágar (método Kirby-Bauer)}

A avaliação de resistência a oxacilina com discos de oxacilina $(1 \mu \mathrm{g})$ e cefoxitina $(30 \mu \mathrm{g})$ demonstrou que todas as amostras de $S$. aureus isoladas dos alunos de enfermagem foram sensíveis à oxacilina. Enquanto isso, das 79 amostras de ECN, 11 (16,2\%) foram resistentes à oxacilina, sendo 10 resistentes aos discos de oxacilina e cefoxitina. Em uma amostra, houve crescimento de colônias dentro do halo de inibição, que foram reisoladas e submetidas à coloração de Gram e aos testes catalase, coagulase e bioquímicos para constatação de sua pureza, confirmando sua heteroresistência.

Das 11 amostras de ECN resistentes, nove $(81,8 \%)$ foram de S. epidermidis, uma (9\%), de S. warneri e uma (9\%), de S. lugdunensis.

Foram utilizadas as cepas padrões $S$. aureus ATCC 33591 (controle positivo, resistente à oxacilina) e ATCC 29213 (controle negativo, sensível à oxacilina).

Conforme demonstrado na Figura 2, nenhuma amostra de $S$. aureus foi resistente à oxacilina, enquanto nos ECN foram encontradas 11 amostras resistentes. $\mathrm{O}$ número de amostras de $\mathrm{ECN}$ resistentes nos alunos do primeiro ano do curso de enfermagem foi de duas amostras, três amostras no segundo ano, quatro, no terceiro e duas, no quarto ano (Figura 3).

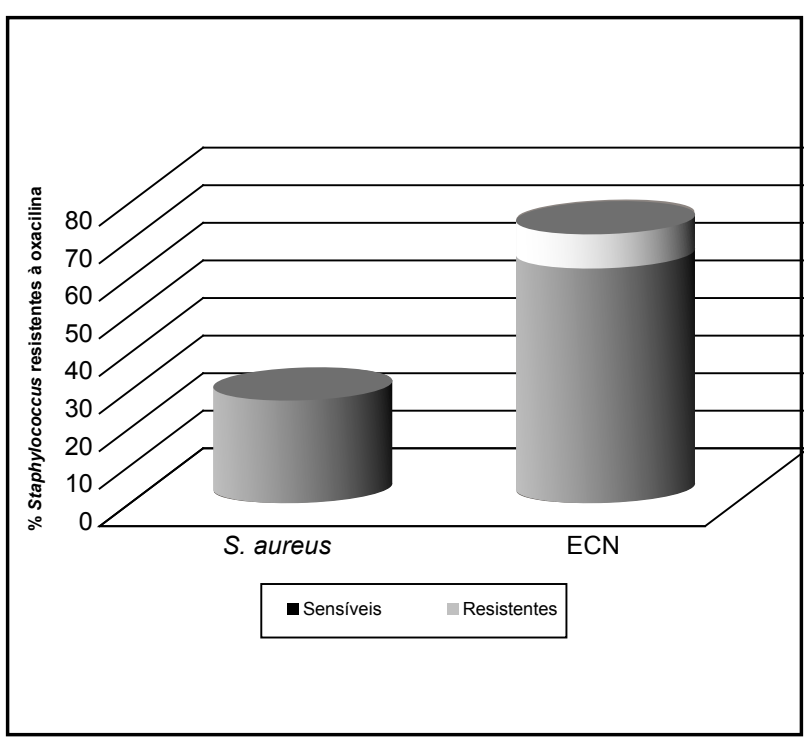

Figura 2 - Perfil de resistência à oxacilina em $\mathrm{S}$. aureus e espécies de ECN isoladas das fossas nasais de alunos do curso de enfermagem da FMB ECN: estafilococos coagulase-negativos; FMB: Faculdade de Medicina de Botucatu. 


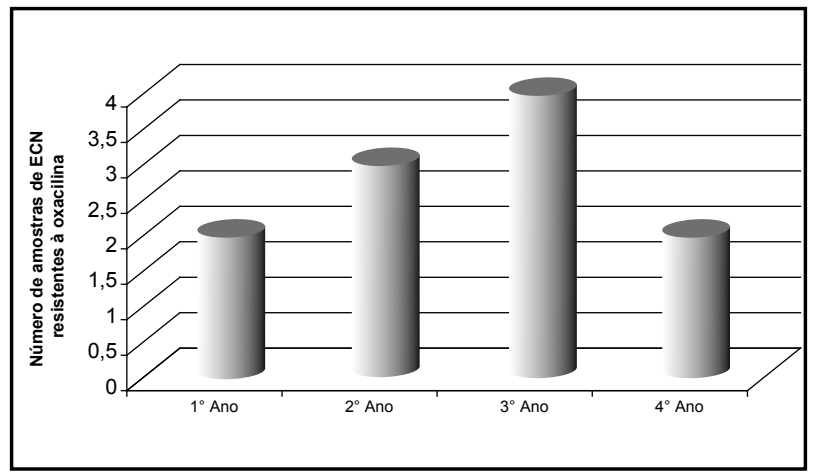

Figura 3 - Perfil de resistência à oxacilina em amostras de ECN isoladas das fossas nasais de alunos do primeiro ao quarto ano do curso de enfermagem da FMB ECN: estafilococos coagulase-negativos; FMB: Faculdade de Medicina de Botucatu.

\section{Detecção do gene mecA de resistência à oxacilina em amostras de $S$. aureus e estafilococos coagulase-negativa isoladas das fossas nasais de alunos do curso de enfermagem}

Amplificação do ácido nucleico e visualização

A amplificação pela técnica de PCR do gene mecA nas amostras de Staphylococcus aureus isoladas de alunos do curso de enfermagem mostrou resultado negativo para presença do gene mecA nas 30 amostras isoladas.

Quanto às amostras de $\mathrm{ECN}$, a amplificação pela técnica de PCR do gene mecA mostrou que as 11 amostras de ECN resistentes à oxacilina no teste de sensibilidade às drogas foram positivas para o gene mecA (533bp), conforme mostra a Figura 4.

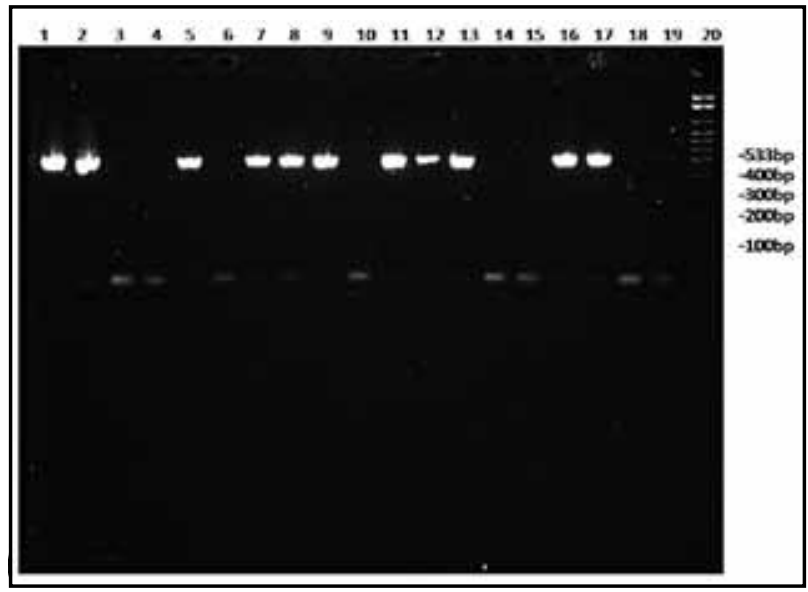

Figura 4 - Eletroforese de gel de agarose para pesquisa do gene mecA (533 bp) 20: marcador de 100 bp, 1 a 2; 5; 7 a 9; 11 a 13; 16 e 19: amostras de ECN isoladas das fossas nasais de alunos do curso de enfermagem da FMB positivas para o gene mecA 3 e 4; 6; 10; 14 e 15 amostras de ECN isoladas das fossas nasais de alunos do curso de enfermagem da FMB negativas para o gene mecA. 18: controle negativo (S. aureus ATCC 29213) e 17: controle positivo (S. aureus ATCC 33591)

ECN: estafilococos coagulase-negativos; FMB: Faculdade de Medicina de Botucatu.

\section{Análise estatística}

De acordo com o cálculo do $\chi^{2}$, não houve significância estatística entre as taxas de portadores de $S$. aureus nos quatro anos do curso de enfermagem, $(p=0,0569)$. A análise estatística demonstrou haver significância apenas das taxas de portadores do primeiro ano para o segundo ano do curso $(p=0,01604)$, em que o número de portadores do primeiro ano foi significativa maior que o do segundo ano.

\section{Discussão}

Os resultados deste estudo demonstraram que de 109 amostras de Staphylococcus coletadas de 104 alunos do curso de graduação em enfermagem, 30 (27,5\%) amostras foram de S. aureus e 79 (72,5\%), de ECN. Os resultados do estudo situam-se dentro dos limites estabelecidos por Goldmann ${ }^{(7)}$, que mostraram incidência de $20 \%$ a $40 \%$ de portadores de S. aureus.

Heshiki et al. ${ }^{(8)}$, em estudo com médicos residentes do Hospital Universitário de Londrina, verificaram que as bactérias mais frequentemente isoladas nas fossas nasais foram Staphylococcus coagulase-negativa (39\%) e Staphylococcus aureus (17\%). Kingdom et al. ${ }^{(11)}$, em estudo para verificar se o tempo de exposição ao ambiente hospitalar influenciava na flora nasal de estudantes de medicina, detectaram $29 \%$ de Staphylococcus aureus no grupo A (estudantes sem exposição), 32\% no grupo B (estudantes com 12 meses de exposição) e $32 \%$ no grupo $C$ (estudantes com 36 meses de exposição). Com relação aos ECN, esses autores encontraram $79 \%$ de $E C N$ no grupo $A, 97 \%$ no grupo B e $94 \%$ no grupo $C$.

O S. epidermidis foi a espécie mais frequentemente isolada $(79,7 \%)$, sendo esse resultado similar aos de outros autores que revelam essa espécie como sendo a mais comumente encontrada colonizando a pele e superfícies mucosas ${ }^{(15)}$. Savolainen et al. ${ }^{(24)}$ também encontraram $62 \%$ de Staphylococcus epidermidis e $34 \%$ de Staphylococcus aureus na flora nasal de 404 indivíduos saudáveis.

Em nosso estudo as taxas de portadores nasais de $S$. aureus, de acordo com o ano de graduação, revelaram para o primeiro ano 13 alunos (43,3\%); para o segundo, três alunos, $(11,1 \%)$; para o terceiro, oito alunos $(33,3 \%)$ e para o quarto ano, seis alunos (26\%). De acordo com os resultados encontrados, não houve relação da taxa de portadores de $S$. aureus com o tempo de envolvimento hospitalar, visto que os alunos do primeiro ano de gra- 
duação que ainda não tiveram contato com o hospital apresentaram um número de portadores 2,16 vezes maior que os alunos do quarto ano.

Resultados obtidos por Santos et al. (1999) ${ }^{(19)}$ também demonstraram que a relação que os alunos de um curso de auxiliar de enfermagem mantinham com o ambiente hospitalar não favoreceu o aumento da taxa de portadores no decorrer do tempo. Hutchison et al. ${ }^{(9)}$ também demonstraram que o envolvimento que enfermeiras mantinham com o hospital, desde treinamento até execução da profissão não influenciou na taxa de portadores de S. aureus. Cinquenta e uma estudantes de enfermagem submeteram-se à pesquisa de $S$. aureus na cavidade nasal, semanalmente, por um período de 18 meses. Oito (16\%) foram consideradas portadoras persistentes, sendo quatro (8\%) da bactéria de mesmo fagótipo e outras quatro (8\%), com fagótipos variáveis ${ }^{(5)}$.

O questionário aplicado em nosso estudo possibilitou verificar alta incidência (76,9\%) de infecções bacterianas nos alunos. Chamou atenção o maior número de infecções bacterianas relatadas pelos alunos do primeiro ano $(96,6 \%)$, os quais também apresentaram maior frequência de portadores de S. aureus. A maior frequência de infecções em alunos portadores pode estar relacionada com diminuição dos mecanismos de defesa do hospedeiro, desencadeando um aumento na proliferação de microrganismos da própria flora, com início de um processo infeccioso.

As infecções das vias aéreas superiores (orofaringite, amigdalite e sinusite) foram as mais frequentes. Costa et al.(2) pesquisaram a flora microbiana, que coloniza as amígdalas de crianças com infecções de repetição, e encontraram $33,3 \%$ de $S$. aureus.

O envolvimento anterior à graduação com instituições hospitalares não apresentou relação com o estado de portador de $S$. aureus, sendo que 14 alunos que responderam o questionário relataram ter desenvolvido atividades no ambiente hospitalar antes da graduação, dos quais somente três $(21,4 \%)$ foram positivos para $S$. aureus. Santos et al. (2000) ${ }^{(20)}$ também demonstraram não haver diferença entre as taxas de portadores dos alunos que não haviam desenvolvido atividades assistenciais antes da graduação com os alunos que haviam, $26,6 \%$ e $26,7 \%$, respectivamente.

Os resultados do teste de sensibilidade às drogas antimicrobianas mostraram que todas as amostras de S. aureus isoladas dos alunos incluídos no estudo foram sensiveis aos discos de oxacilina e cefoxitina, evidenciando a possibilidade das cepas serem comunitárias.
Quanto aos ECN, o S. epidermidis foi a espécie que apresentou maior número de resistência à oxacilina, das 11 amostras resistentes, nove $(81,8 \%)$ eram de $S$. epidermidis. Michelim et al. ${ }^{(16)}$ também encontraram alta taxa de S. epidermidis multirresistentes (76,5\%) em amostras clínicas de pacientes da unidade neonatal $(67,7 \%)$, pacientes da pediatria $(66,6 \%)$ e unidade de adultos $(60,8 \%)$. Lancellotti ${ }^{(13)}$, pesquisando cepas de Staphylococcus spp. isoladas de mãos e cavidade nasal de dentistas, encontrou $88 \%$ das cepas resistentes à oxacilina.

Entre as amostras de ECN, foram obtidas 10 amostras resistentes à oxacilina, de acordo com o teste de difusão da droga em discos, confirmado pela detecção do gene mecA nessas mesmas amostras. Foi encontrada uma amostra heterorresistente, que pelo antibiograma foi detectada por meio do crescimento de colônias dentro do halo de inibição, sendo a confirmação de resistência dada pela confirmação da presença do gene mecA. A heterorresistência à oxacilina também foi verificada por Junqueira ${ }^{(10)}$, que encontrou, em 30 cepas sensíveis à meticilina pelo antibiograma, sete $(23,3 \%)$ positivas para o gene mecA, sugerindo a heterorresitência nessas amostras.

$\mathrm{O}$ teste de sensibilidade às drogas com discos de difusão apresentou $90,9 \%$ de sensibilidade e especificidade, confirmando a necessidade do conhecimento das características genotípicas, como a detecção do gene mecA ou da proteína codificada por esse gene (PBP 2a), pois são os testes mais adequados para determinação de resistência à oxacilina e podem ser utilizados para confirmar os resultados obtidos pelos testes com disco(1).

O que ocorre quanto ao método de discos de difusão é que a expressão fenotípica de resistência em células contendo mecA pode variar, ocorrendo o que chamamos de heterorresistência, que ocorre quando uma pequena população de células (usualmente 0,1 a 0,01\%) é resistente à oxacilina, enquanto a maioria da população é morta por baixas concentrações do antibiótico. Assim sendo, uma amostra pode apresentar frequência variável de células individualmente sensíveis e resistentes a essa droga, dificultando a detecção pelo antibiograma ${ }^{(6)}$.

A maior taxa de $\mathrm{ECN}$ resistentes foi verificada no terceiro ano do curso de enfermagem, o primeiro e o quarto anos apresentaram as menores taxas, o que confirma os resultados já obtidos, de que o envolvimento hospitalar durante a graduação não influencia no aumento da taxa de portadores de Staphylococcus resistentes à oxacilina.

Este trabalho resgata a importância das vias aéreas superiores na transmissão e aquisição de microrganismos 
patogênicos e a necessidade de se investir na educação continuada e no controle bacteriológico periódico das pessoas que trabalham em ambiente hospitalar, garantindo boas práticas de controle de infecção durante a prestação de assistência aos pacientes e diminuição dos casos de infecções por esses agentes.

$\mathrm{O}$ aluno de enfermagem representa um exemplo que se enquadra dentro dessas considerações, já que durante a sua formação responsabiliza-se pela assistência ao paciente, em diferentes níveis de complexidade, sendo essa assistência, pelas características do trabalho manual, que requer esforço e proximidade física entre ele e o paciente, aumentando as oportunidades favoráveis à disseminação de microrganismos e expondo ambos a determinados riscos de aquisição de doenças.

\section{Agradecimentos}

À Fundação de Amparo à Pesquisa do Estado de São Paulo (FAPESP) pelo suporte financeiro (Processo 2006/04460-2).

\section{Referências}

1. CLSI. 2008. Performance standards for antimicrobial susceptibility testing. CLSI approved standard M100-S15. Clinical and Laboratory Standards Institute, Wayne, PA.

2. COSTA, F. N. etal. Estudo microbiológico do core e superfície das amígdalas palatinas em crianças portadoras de faringoamigdalites de repetição e hipertrofia adenoamigdaliana. Rev. Bras. Otorrinolaringol, v. 69, n. 2, p.181-4, 2003.

3. CUNHA, M. L. R. S.; SINZATO, Y. K.; SILVEIRA, L. V. A. Comparison of methods for the identification of coagulase-negative Staphylococci. Mem Inst Oswaldo Cruz, v. 99, n. 8, p. 855-60, 2004.

4. DAVIS, B. D. et al. Relações hospedeiro-parasita nas doenças bacterianas. In: DAVIS, B. D. et al. Microbiologia: Infecções bacterianas e micóticas. São Paulo: Edart, 1973. Cap. 19; p. 9-54.

5. DUNCAN, I. B. R. et al. Nasal carriage of Staphylococcus pyogenes by student nurses. Can Med Assoc J, v. 77, n. 11, p. 1001-09, 1957.

6. FINAN, J. E. et al. Conversion of oxacillin resistant Staphylococcifrom heterotypic to homotypic resistance expression. Antimicrobiol Agent Chemotherapy, v. 46, n. 1, p. 24-30, 2001.

7. GOLDMANN, D. A. Epidemiology of Staphylococcus aureus and group a Streptococci. In: BENNETT, J. V. Hospital Infections. Boston: Littie Brown and Company, 1992. p. 767-87.

8. HESHIKI, Z. et al. Flora bacteriana nasal: estudo entre médicos residentes dos Hospitais Universitários de Londrina - Paraná. Semina: Ciências Biológicas e da Saúde, v. 23, n. 1, p. 3-10, 2002.

9. HUTCHISON, J. G. P.; GREEN, C.A.; GRIMSON, T. A. Nasal carriage of Staphylococcus aureus in nurses. J. Clin Path, v. 10, n. 1, p. 92-5, 1957.

10. JUNQUEIRA, A. L. N. Prevalência de estafilococos resistentes a meticilina em profissionais de saúde de uma Unidade de Terapia Intensiva de Goiânia - Goiás. Revista Eletrônica de Enfermagem, v. 4, n. 1, 2002. Disponível em: <http://www.revistas.ufg.br/index.php/fen>. Acesso em: 25 maio 2007.
11. KINGDOM et al. (Dublin). Staphylococcus aureus nasal carriage in medical students with varying clinical exposure. J. Hosp. Infection, v. 4, n. 1, p. 75-9, 1983

12. KONEMAN, E. W. et al. Color atlas and textbook of diagnostic microbiology. 5. ed. Philadelphia: Lippincott; 1997.

13. LANCELLOTTI, M. Estudo epidemiológico deStaphylococcus spp. em ambientes, água e portadoes sadios e determinação da sensibilidade a antimicrobianos. Tese (Doutorado) - Faculdade de Ciências Agrárias e Veterinárias, Universidade Estadual Paulista (UNESP), Jaboticabal, 2006.

14. MARTINS, A.; CUNHA, M. L. R. S. Methicillin resistance in Staphylococcus aureus and coagulase-negative Staphylococci: epidemiological e molecular aspects. Microbiol Immunol, v. 51, n. 9, p. 787-95, 2007.

15. MARTINS, L.T. Staphylococcus. In: TRABULSI, L.R. et al. Microbiologia. 3. ed. São Paulo: Atheneu, 1999. Cap. 18; p. 149-55.

16. MICHELIM, L. et al. pathogenicity factors and antimicrobial resistance of Staphylococcus epidermidis associated with nosocomial infections occurring in intensive care units. Brazilian J Microbiol, v. 36, n. 1, p. 1723, 2005

17. MURAKAMI, K. et al. Identification of methicillin-resistant strains of Staphylococci by polymerase chain reaction. J Clin Microbiol, v. 29, n. 10, p. 2240-4, 1991.

18. ROUQUAYROL, M. Z.; VERAS, F. M. F. Doenças transmissíveis e modos de transmissão. In: ROUQUAYROL. Epidemiologia e saúde. 4. ed. Rio de Janeiro: MEDSI, 1993. Cap. 8; p. 217-68.

19. SANTOS, B. M. O. Estudo longitudinal sobre portador são de Staphylococcus aureus em alunos de um curso de auxiliar de enfermagem. Rev Soc Bras Med Trop, v. 32, n. 4, p. 1-6, 1999.

20. SANTOS, B. M. O. Monitoramento da colonização pelo Staphylococcus aureus em alunos de um curso de auxiliar de enfermagem durante a formação profissional. Rev. Latino Am Enfermagem, v. 8, n. 1, p. 67-73, 2000. 
21. SANTOS, B. M. O.; AGUILLAR, O. M.; TAKAKURA, M. S. Colonização simultânea de Staphylococcus aureus na cavidade nasal e mãos de portadores sãos de um hospital escola. Rev Microbiol, v. 21, n. 4, p. 309-14, 1990.

22. SANTOS, B. M. O.; SCOCHI, C. G. S.; SOUZA, M. T. G. Prevalência de portadores sãos de Staphylococcus aureus em pessoal de enfermagem de unidades pediátricas de um hospital geral escola. Parte I. Rev Pauli Hosp, v. 38, p. 24-9, 1990.

23. SANTOS, B. M. O.; SOLÉ-VERNIN, C. Papel epidemiológico dos portadores sãos de Staphylococcus aureus como fonte de infecção. Rev Inst Med Trop, v. 23, n. 5, p. 217-24, 1981.

24. SAVOLAINEN, S.; YLIKOSHI, J.; JOUSIMLES, S. The bacterial flora of the nasal cavity in healthy young men. Rhinology, v. 24, n. 4, p. 249-55, 1986. 